\section{Short-term memory: Are item and position information stored independently?}

\author{
GEOFF CUMMINGI and MAX \\ COLTHEART, Monash University, Vic- \\ toria, Australia
}

\begin{abstract}
Arrays consisting of six digits placed at a random six of the nine positions of a 3 by 3 grid were presented tachistoscopically. After a retention interval, Ss gave two responses, one concerming the identity of the digits presented, and the other concerning the grid positions occupied. Results suggest that the position of an item in the array and the identity of the item are stored as a unit and are forgotten or retained together.
\end{abstract}

Sperling (1963, 1967) postulated a two-stage model of short-term memory for visually presented material. According to this model, items are input in parallel from the visual display into a two-dimensional visual information store (VIS); they may then be transferred serially into an auditory information store (AIS), in which they are held in strings. Although AIS may contain one or more strings of items, storage in AIS is essentially sequential (one-dimensional) because items are main tained in AIS by rehearsal, which is a serial process.

The position of an item in a twodimensional visual display may be coded directly as position in two-dimensional VIS. However, when items are transferred to AIS, position information must be recoded in some way if it is to be retained in this one-dimensional store.

Four classes of theories about the operation of AIS in this situation may be distinguished. These classes may be defined in terms of four possible relationships between the processing of information about the identity of an item (I) and the processing of information about its position in the stimulus array $(\mathrm{P})$. These four relationships may be labelled and summarized thus:

(1) HI: Processing of I and P are independent. Specifically, the probability of correct recall of $I$ is the same whether or not $\mathrm{P}$ is correctly recalled, and vice versa. For example, one theory in this class postulates that $I$ and $P$ are stored in separate strings and so may be forgotten separately.

(2) HIP: Correct recall of I implies correct recall of $P$, but the converse is not necessarily true. Equivalently, I may be forgotten without $P$ being forgotten, but not vice versa. For example, $\mathbf{S}$ may say, "The upper right corner was occupied, but I forget what was in it." This might occur because items are stored in pigeon-holes which correspond to positions in the input array, and a stored item can decay until it is not possible to retrieve it, although it is still possible to detect that something was stored in that pigeon-hole.

(3) HPI: Correct recall of P implies correct recall of $I$, but the converse is not necessarily true. Equivalently, $\mathrm{P}$ may be forgotten without I being forgotten, but not vice versa. For example, S may say, "A 4 appeared but I don't know where." This might occur because I information is easy to store whereas recoded $\mathbf{P}$ information is difficult to store and impossible to store without being tied to I.

(4) HC: I storage and P storage are fully contingent. If $I$ is forgotten, so is $P$, and vice versa; it is as if $I$ and $P$ were written on the same tag, which may be either retained or lost, but cannot be torn in two.

In any experiment aimed at distinguishing among these possibilities, recall must be exclusively from AIS, and responses conveying $I$ and $P$ information separately must be required. An experiment satisfying these requirements was designed accordingly.

The visual display consisted of a 3 by 3 matrix containing six different digits and three vacant cells. A typical digit array is shown in Fig. 1A. For each digit array there was a corresponding response array, such as the one shown in Fig. 1B. One of the two digits in the response array had appeared in the previous digit array, and the other had not. Similarly, one of the positions specified by a circle in the response array had been occupied by a digit in the digit array, and the other had not. In fact, this marked position had been occupied by the one of the two digits in the response array which had appeared in the previous digit array.

The $S$ responded by naming the digit which had appeared in the preceding digit array, and the position which had been occupied; the latter response was made by naming the color of the circle marking the occupied position.

Thus the correct response for the pair of arrays shown in Fig. 1 was "seven black" or "black seven" since a 7 had appeared in the center position of the digit array. The response "red five" or "five red" represents both an item error and a position error. The other possible responses were "black five" (position correct, item wrong) and "red seven" (position wrong, item right). In the instructions to $\mathrm{Ss}$, equal emphasis was given to I and $\mathrm{P}$ responses, and the two possible orders of response were stated to be equally correct.

Immediately after the offset of any digit array, and before the onset of the corresponding response array, a "visualnoise" array was presented. Its purpose was to erase the digits from VIS and so ensure that subsequent responses were made entirely from AIS. The visual-noise array consisted of digits superposed in various orientations, and is shown in Fig. 1C.

About 300 digit- and response-array pairs, and one visual-noise array, were made up with black Letraset digits on white cards. They were viewed with the preferred eye in a two-field Pullin "Cambridge" tachistoscope. The brightness of each field was about $5 \mathrm{ft}-\mathrm{L}$ and the viewing distance about $35 \mathrm{~cm}$, so that the fields subtended a visual angle of about $15 \mathrm{deg}$ (horizontally) by $9 \mathrm{deg}$.

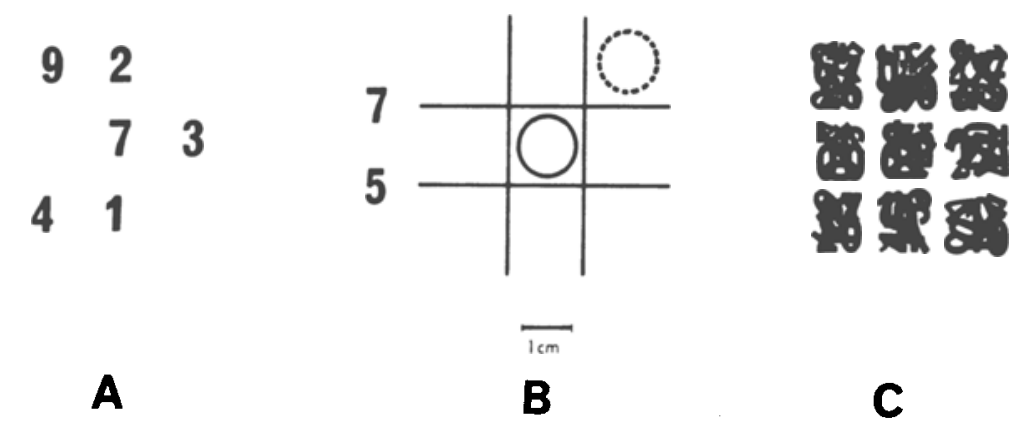

Fig. 1. A typical array pair. (A) is the digit array and (B) the corresponding response array. Array (C) is the visual-noise field, presented immediately after each digit array. Ss responded by naming one of the digits, "seven" or "five," and one of the colors, "black" (solid circle) or "red" (broken circle). Their task was to name the digit which had appeared in the digit array and the color corresponding to the position in which it had appeared. 
Nine undergraduates served as Ss. Each had 30 practice trials and 100 experimental trials in one session and a further 100 experimental trials in a second session. For one session (randomly chosen to be the first or second) the exposure time was $70 \mathrm{msec}$ and for the other it was $80 \mathrm{msec}$. Ss could take a rest at will. After any rest period two warm-up trials were given. The same 200 pairs of digit and response arrays were used for the experimental trials of all Ss, and responses on these trials were the only ones used in the data analysis.

At the beginning of a trial, the visual-noise array was visible. The $S$ fixated the center of the visual-noise array and initiated the trial by pressing a switch. The digit array was immediately exposed for $70 \mathrm{msec}$ or $80 \mathrm{msec}$. The noise field was then visible for $2 \mathrm{sec}$, after which the response array was visible for as long as was required for the $S$ to respond. Then $E$ switched back to the noise field in preparation for the next trial.

Although a consistent order of report was not required, each $S$ did in fact always use one order of report. Table $1 \mathrm{~A}$ gives the order of report adopted by each $S$, and shows that four Ss always gave their $P$ response first and five always gave their $I$ response first. Order of report did not appear to be correlated with any other feature of behavior. In particular, just six Ss (of whom three gave I first and three gave $P$ first) achieved a higher percentage of correct responses on the dimension (I or P) reported first.

For analysis, each response was classified into one of four categories, according to whether I was correct or not and to whe ther $\mathbf{P}$ was correct or not. The resulting 2 by 2 contingency tables for each $S$ are shown in Table 1B. The observed marginal totals of correct $I$ and $P$ responses show that the experimental conditions were such that Ss could achieve only poor absolute accuracy. Averaging over $S$ s and response types (I and P), and correcting for guessing, accuracy was only $19 \%$. This is equivalent to the item and position of 1.2 digits, out of a possible 6 digits, being processed correctly. So any conclusions drawn from these data may not be relevant when performance levels are high.

Assuming independence between successive responses of any $S$ we may use $\chi^{2}$ statistics to examine the appropriateness of the four hypotheses about the relationship between the processing of item information and the processing of position information. Table 1 also shows the $\chi^{2}$ value, for each $S$, under each of the four hypotheses and the probability (in italics) of obtaining a value of $\chi^{2}$ this large or larger if the relevant hypothesis were true.

The expected frequencies for these $\chi^{2}$

Table 1

Analysis of the responses of individual Ss by response category (B). Columns (C)-(F) give, for each hypotheses, $\chi^{2}$ values and (in italics) the probability of obtaining a $\chi^{2}$ value at least this large.

\begin{tabular}{|c|c|c|c|c|c|c|c|c|}
\hline $\begin{array}{l}\text { Subject } \\
\text { (Order of } \\
\text { report } \\
\text { adopted } \\
\text { by S.) }\end{array}$ & $\begin{array}{l}\text { I } \checkmark \\
\text { IX }\end{array}$ & $\begin{array}{l}\text { Respor } \\
\text { PJ } \\
a \\
c \\
a+c\end{array}$ & $\begin{array}{l}\text { requen } \\
P x \\
b \\
d \\
b+d\end{array}$ & $\begin{array}{l}a+b \\
c+d \\
200\end{array}$ & $\begin{array}{l}\chi^{2} \mathrm{HI} \\
(\mathrm{df}=1)\end{array}$ & $\begin{array}{l}\chi^{2} \text { HIP } \\
(\mathrm{df}=1)\end{array}$ & $\begin{array}{l}\chi^{2} \text { HPI } \\
(\mathrm{df}=1)\end{array}$ & $\begin{array}{l}\chi^{2} \mathrm{HC} \\
(\mathrm{df}=2)\end{array}$ \\
\hline $\mathbf{A}$ & & & $\mathbf{B}$ & & $\mathrm{C}$ & $\mathrm{D}$ & $\mathbf{E}$ & $\mathrm{F}$ \\
\hline $\begin{array}{c}\text { KA } \\
(\mathrm{P}, \mathrm{I})\end{array}$ & & $\begin{array}{r}81 \\
40 \\
121\end{array}$ & $\begin{array}{l}33 \\
46 \\
79\end{array}$ & $\begin{array}{r}114 \\
86 \\
200\end{array}$ & $\begin{array}{l}12.3 \\
0.004\end{array}$ & $\begin{array}{l}2.14 \\
0.14\end{array}$ & $\begin{array}{l}0.42 \\
0.51\end{array}$ & $\begin{array}{l}2.14 \\
0.34\end{array}$ \\
\hline $\begin{array}{r}R B \\
(P, I)\end{array}$ & & $\begin{array}{r}73 \\
49 \\
122\end{array}$ & $\begin{array}{l}38 \\
40 \\
78\end{array}$ & $\begin{array}{r}111 \\
89 \\
200\end{array}$ & $\begin{array}{l}2.38 \\
0.13\end{array}$ & $\begin{array}{l}0.05 \\
0.82\end{array}$ & $\begin{array}{l}0.91 \\
0.34\end{array}$ & $\begin{array}{l}1.62 \\
0.44\end{array}$ \\
\hline$(I, P)$ & & $\begin{array}{r}88 \\
34 \\
122\end{array}$ & $\begin{array}{l}35 \\
43 \\
78\end{array}$ & $\begin{array}{r}123 \\
77 \\
200\end{array}$ & $\begin{array}{c}14.9 \\
0.001\end{array}$ & $\begin{array}{l}0.82 \\
0.37\end{array}$ & $\begin{array}{l}1.05 \\
0.30\end{array}$ & $\begin{array}{l}1.30 \\
0.52\end{array}$ \\
\hline $\begin{array}{r}\text { DH } \\
(\mathrm{I}, \mathrm{P})\end{array}$ & & $\begin{array}{r}72 \\
42 \\
114\end{array}$ & $\begin{array}{l}39 \\
47 \\
86\end{array}$ & $\begin{array}{r}111 \\
89 \\
200\end{array}$ & $\begin{array}{l}6.30 \\
0.01\end{array}$ & $\begin{array}{l}0.74 \\
0.39\end{array}$ & $\begin{array}{l}2.81 \\
0.09\end{array}$ & $\begin{array}{l}0.77 \\
0.68\end{array}$ \\
\hline $\begin{array}{r}\text { SH } \\
(\mathrm{P}, \mathrm{I})\end{array}$ & & $\begin{array}{r}74 \\
48 \\
122\end{array}$ & $\begin{array}{l}33 \\
45 \\
78\end{array}$ & $\begin{array}{r}107 \\
93 \\
200\end{array}$ & $\begin{array}{l}6.44 \\
0.01\end{array}$ & $\begin{array}{l}1.85 \\
0.17\end{array}$ & $\begin{array}{l}0.10 \\
0.75\end{array}$ & $\begin{array}{l}3.00 \\
0.22\end{array}$ \\
\hline $\begin{array}{r}\mathrm{GJ} \\
(\mathrm{I}, \mathrm{P})\end{array}$ & & $\begin{array}{l}63 \\
35 \\
98\end{array}$ & $\begin{array}{r}44 \\
58 \\
102\end{array}$ & $\begin{array}{r}107 \\
93 \\
200\end{array}$ & $\begin{array}{l}8.99 \\
0.003\end{array}$ & $\begin{array}{l}1.92 \\
0.17\end{array}$ & $\begin{array}{l}5.69 \\
0.02\end{array}$ & $\begin{array}{l}5.89 \\
0.05\end{array}$ \\
\hline $\begin{array}{r}\text { BL } \\
(I, P)\end{array}$ & & $\begin{array}{r}78 \\
34 \\
112\end{array}$ & $\begin{array}{l}45 \\
43 \\
88\end{array}$ & $\begin{array}{r}123 \\
77 \\
200\end{array}$ & $\begin{array}{l}7.13 \\
0.008\end{array}$ & $\begin{array}{l}0.04 \\
0.84\end{array}$ & $\begin{array}{r}1.05 \\
\text { s } 0.31\end{array}$ & $\begin{array}{l}1.69 \\
0.43\end{array}$ \\
\hline $\begin{array}{c}\text { JS } \\
(\mathrm{P}, \mathrm{I})\end{array}$ & & $\begin{array}{r}111 \\
34 \\
145\end{array}$ & $\begin{array}{l}35 \\
20 \\
55\end{array}$ & $\begin{array}{r}146 \\
54 \\
200\end{array}$ & $\begin{array}{l}3.38 \\
0.07\end{array}$ & $\begin{array}{l}4.10 \\
0.04\end{array}$ & $\begin{array}{l}3.63 \\
0.06\end{array}$ & $\begin{array}{l}4.94 \\
0.08\end{array}$ \\
\hline $\begin{array}{c}\text { IT } \\
(\mathrm{I}, \mathrm{P})\end{array}$ & & $\begin{array}{r}71 \\
68 \\
139 \\
\end{array}$ & $\begin{array}{l}16 \\
45 \\
61\end{array}$ & $\begin{array}{r}87 \\
113 \\
200\end{array}$ & $\begin{array}{l}10.6 \\
0.001\end{array}$ & $\begin{array}{l}13.8 \\
0.0002\end{array}$ & $\begin{array}{l}4.68 \\
0.03\end{array}$ & $\begin{array}{l}31.6 \\
<10^{5}\end{array}$ \\
\hline \multicolumn{5}{|c|}{ Total chi-square values } & $\begin{array}{l}72.4 \\
(\mathrm{df}=9) \\
<10^{-}\end{array}$ & $\begin{array}{l}25.5 \\
(\mathrm{df}=9) \\
0.003\end{array}$ & $\begin{array}{c}20.3 \\
(\mathrm{df}=9) \\
0.02\end{array}$ & $\begin{array}{l}53.0 \\
(\mathrm{df}=18) \\
<10^{-4}\end{array}$ \\
\hline \multicolumn{5}{|c|}{ Total (excluding IT) } & $\begin{array}{l}61.8 \\
(\mathrm{df}=8)_{5} \\
<10^{-}\end{array}$ & $\begin{array}{c}11.7 \\
(\mathrm{df}=8) \\
0.16\end{array}$ & $\begin{array}{l}15.7 \\
(\mathrm{df}=8) \\
0.05\end{array}$ & $\begin{array}{c}21.4 \\
(\mathrm{df}=16) \\
0.16\end{array}$ \\
\hline
\end{tabular}

calculations were obtained as follows:

(1) HI. The expected frequencies here are the usual expected frequencies for a 2 by 2 contingency table, and $\mathrm{df}=1$.

(2) HIP. If this hypothesis is true, then, if a $P$ error is made, the $I$ response must be a guess, in which case the expected frequencies are as shown in Table 2D, where e is estimated by $1 / 2(b+d)=1 / 2(N-a-c)$. Knowledge of the values of $a, c$, and $N$ is used in calculating the expected frequencies and so $\mathrm{df}$ is $4-3=1$.

(3) HPI. Similarly, if this hypothesis is true, then if an I error is made, the $P$ response must be a guess, in which case the expected frequencies are as shown in Table $2 \mathrm{E}$, where $\mathrm{f}$ is estimated by $1 / 2(c+d)=1 / 2(N-a-b)$. Knowledge of the values of $a, b$, and $N$ is used in calculating the expected frequencies, and so $\mathrm{df}$ is $4-3=1$.

(4) HC. Under this hypothesis, $S$ is able to give both a correct $I$ response and a correct $\mathrm{P}$ response, or else he guesses. Table $2 \mathrm{~F}$ gives the expected frequencies in this case, and $g$ is estimated by $g=(b+c+d) / 3=(N-a) / 3$. Knowledge of the values of $\mathrm{a}$ and $\mathrm{N}$ is used in calculating the expected frequencies, and so $\mathrm{df}$ is $4-2=2$.

Table 1 indicates that S IT gave correct I responses at a level considerably below that expected by chance. Whatever the reason for this, it does suggest that the results for S IT should be excluded from the analysis or at least considered separately.

The bottom row of Table 1 gives, for each hypothesis, the sum of the individual $\chi^{2}$ values for the eight Ss whose data are being considered. The small probability associated with the $\chi^{2}$ value in Column C leads to rejection of $\mathrm{HI}$. The corresponding values for HIP and HPI are the bottom entries in Columns D and E, and suggest that HIP may provide a reasonable fit to the data, while $\mathrm{HPI}$ is on the borderline between acceptance and rejection. But acceptance of both HIP 
Table 2

(B): Observed frequencies. for an individual S, of responses placed in categories according to whether $I$ and $P$ responses are right or wrong. (D). (E), and (F): Frequencies expected under HIP, HPI, and HC, respectively

\begin{tabular}{|c|c|c|c|c|c|c|c|c|}
\hline $\begin{array}{rll} & \text { P } & \text { Px } \\
\text { IN } & a & b \\
\text { Ix } & c & d \\
\end{array}$ & & $\begin{array}{l}\mathrm{PV} \\
\mathrm{IV} \text { a } \\
\mathrm{I} \times \mathrm{c} \\
\end{array}$ & $\begin{array}{l}\text { Px } \\
e \\
e \\
\end{array}$ & $\begin{array}{r}P J \\
I J a \\
I \times f \\
\end{array}$ & $\begin{array}{l}\mathrm{Px} \\
\mathrm{b} \\
\mathrm{f} \\
\end{array}$ & $\begin{array}{l}\text { PJ } \\
I J a \\
I \times g \\
\end{array}$ & $\begin{array}{l}P \times \\
g \\
g\end{array}$ & \\
\hline (B) & 200 & & (D) 200 & & (E) 200 & & (F) & 200 \\
\hline
\end{tabular}

and HPI is equivalent to acceptance of $\mathrm{HC}$, and the entry in Column F shows that HC does indeed provide a satisfactory fit to the data.

The probability values for the eight individual $S s$ under each of the four hypotheses confirm these general conclusions: All but two of the eight values in Column $C$ of Table 1 are less than 0.05 ; all but two of the 16 values in Columns $D$ and $E$ are greater than 0.05 ; and all eight values in Column $F$ are greater than 0.05 .

Our results, then, indicate that when items are presented tachistoscopically in a two-dimensional display, and when recall is from short-term memory (AIS) rather than from a peripheral sensory store (VIS), the hypothesis that the position of an item in the display and the identity of the item are stored as a unit and forgotten or retained together fits the data much better than any of the other three hypotheses considered.

\section{REFERENCES}

SPERLING, G. A model for visual memory tasks. Human Factors, 1963, 5, 19-31.

SPERLING, G. Successive approximations to a model for short-term memory. In A. F. Sanders (Ed.), Attention and performence. Amsterdam: North Holland Publishing Co., 1967. NOTE

1. Now at the Institute of Experimental Psychology, Oxford.

\section{Visual temporal discrimination: A point of order}

\section{CARL E. SHERRICK, Princeton University Princeton, N.J. 08540}

The discrepancies in results between no experiments on the visual detection of temporal order are discussed, and it is suggested that the differences arise in great part from the definition of interstimulus interval. The controversy resulting from the misunderstanding is reviewed briefly but optimistically.

Recently there has appeared a series of papers concerned with the question of the visual perception of temporal order under conditions of dichoptic viewing (Robinson, 1967a, b, 1968; Thor, 1967, 1968). In brief, these authors have disagreed on the interpretation of findings of Robinson (1967a). The results of Hirsh \& Sherrick (1961), that flashes must be separated by about $20 \mathrm{msec}$ for correct order to be judged, were replicated successfully by Robinson when he adopted their binocular viewing conditions. Robinson found in addition that under haploscopic viewing conditions (dichoptic observation), “. . all Ss correctly perceived presentation order 100 percent of the time at all intervals except 0 [1967a, p. 1264]." Thor (1967) was unable to replicate Robinson's results, but in a later publication (1968) reported that one $O$ improved his performance in detecting order at the 0 -msec interval between stimuli by adopting a viewing strategy in which ". . . the images of triangle and square appeared in slightly different locations in visual space ... the $S$ attended to apparent movement, and the direction of apparent movement served as the cue to order of presentation [1968, p. 41]." Robinson (1968) has reiterated his view that the important point concerns central versus peripheral processing, and that, "...the basic research question is one of central temporal resolution capabilities ... [1968, p. 247]."

I find myself in agreement with Dr. Robinson, and indeed Hirsh and I affirmed his point of view in the original paper, when we stated that there seems to be," . . some kind of time-organizing system that is both independent of and central to the sensory mechanisms [1961, p. 431]." There is one small technical point that needs clearing up, and, I believe, will lend perspective to the controversy between Robinson and Thor.

In the experiments of Hirsh and Sherrick the flash durations were $5 \mathrm{msec}$, and the interval of the limen for order (ca. $20 \mathrm{msec}$ ) was taken as the time from the onset of the first stimulus to the onset of the second. Robinson's (1967a) flash durations were $10 \mathrm{msec}$, and his interstimulus intervals $(0$. $5,10,20 \mathrm{msec}$, etc.) should be read, in Hirsh and Sherrick's terms, as 10, 15,20.30 msec, etc. Robinson, in order words, was employing the traditional "dark interval" of visual research for his values. (I am indebted to Dr. Richard Gilson for pointing out this discrepancy.) The differences in results are therefore not as large as they first seemed (Robinson's limen ca. $15 \mathrm{msec}$ vs Hirsh and Sherrick's limen ca. $20 \mathrm{msec}$ ). If one assumes a standard error of estimate of 3 to $6 \mathrm{msec}$ for the conditions and number of $\mathrm{Os}$ involved, the differences may not even be significant for the series of experiments under discussion, including the binocular results of Robinson, which now appear to be $10 \mathrm{msec}$ longer than the limen obtained by Hirsh and Sherrick.

The foregoing is not meant to imply that Robinson and Thor have been tilting over a dubious cause. On the contrary, they have by their research techniques opened new avenues of inquiry that should be followed. It is certainly true that such parameters of the stimulus as duration of flash (Thor \& Spitz, 1968), retinal locus (Rutschmann, 1966; Robinson, 1967; Thor, 1967, 1968), and form quality of the image (Robinson, 1967; Thor \& Spitz, 1968) may affect the limen for order. In addition, the $O$ 's learning of specific viewing strategies, which can reduce the limen for order by significant amounts (Hirsh \& Fraisse, 1964; Thor, 1968), deserves further research in its own right; sensory psychology has too long assumed that the training preceding testing is a vague learning process that does not vary over Os, modalities, perceptual dimensions, or experimental conditions. It is time that the set we call a "control variable" be examined for possible plurality of membership, and we are indebted to Drs. Robinson and Thor for underscoring the need.

\section{REFERENCES}

HIRSH, I. J., \& FRAISSE, P. Simultanéité et succession de stimuli hétérogenes. Année psychologique, 1964, 64, 1-19.

HIRSH, I. J., \& SHERRICK, C. E., JR. Percived order in different sense modalities. Joumal of Experimental Psychology, 1961, 62, 423432.

ROBINSON, D. N. Visual discrimination of temporal order. Science, 1967a, 156, 1263-1264.

ROBINSON, D. N. Dichoptic viewing and temporal discrimination: An attempted replication. Science, 1967b, 158, 1704-1705.

ROBINSON, D. N. Assessments of temporal discrimination in vision. Psychonomic Science, 1968, 13, 247.

RUTSCHMANN, R. Perception of temporal order and relative visual latency. Science, 1966, 152. 1099-1101.

THOR, D. H. Dichoptic viewing and temporal discrimination: An attempted replication. Stience, 1967, 158, 1704-1705.

THOR. D. H. Observer strategies in dichoptic view ing of successive stimuli. Psychonomic Science. 1968, 12,41-42.

THOR. D. H., \& SPITZ, H. H. Temporal discrimination as a function of total presentation time. Psychonomic Science, 1968, 13 , 291-292. 